\title{
Marcadores discursivos de base verbal: duas hipóteses de mudança em casos do verbo "crer"
}

DOI: http://dx.doi.org/10.21165/el.v50i1.3056

\section{Lucas Borel Cristiano' \\ Solange de Carvalho Fortilli ${ }^{2}$}

\section{Resumo}

O objetivo deste artigo é tratar de duas possíveis trajetórias de mudança geradoras de marcadores discursivos (MD) no português, em específico, marcadores de base verbal. À primeira, encabeçada por Thompson e Mulac (1991) e bastante aceita em estudos sobre o tema, será relacionada uma segunda, advinda de Brinton (1996, 2008, 2017). Esboçando uma possível associação a quadro de mudança mais recente, contemplado pelos estudos da gramática de construções diacrônica (TRAUGOTT; TROUSDALE, 2013), apontamos a diferença entre reanálise e neoanálise dentro das trajetórias levantadas. Utilizamos o verbo crer $_{M D}$ para a demonstração de uma outra análise acerca da mudança linguística envolvendo o percurso verbo > marcador. Nossos encaminhamentos são no sentido de considerar outras fontes para a emergência de marcadores de base verbal, diferentes das que são mais amplamente defendidas até o momento.

Palavras-chave: verbos cognitivos; verbo crer; marcadores discursivos; mudança linguística; oração adverbial.

1 Universidade Federal de Mato Grosso do Sul (UFMS), Três Lagoas, Mato Grosso do Sul, Brasil; mrlucasborel@outlook.com; https://orcid.org/0000-0002-8758-4832

2 Universidade Federal de Mato Grosso do Sul (UFMS), Três Lagoas, Mato Grosso do Sul, Brasil; fortilli@gmail.com; https://orcid.org/0000-0002-8348-4359 


\title{
Verbally based discourse markers: two hypotheses of language change in usages of the verb "crer" (to believe)
}

\begin{abstract}
The purpose of this article is to address two possible trajectories of change that generate discourse markers (MD) in Portuguese, specifically, verbal-based markers. The first, headed by Thompson and Mulac (1991) and widely accepted in studies on the topic, will be related to a second, coming from Brinton $(1996,2008,2017)$. Outlining a possible association with a more recent field of change, contemplated by studies of the diachronic construction grammar (TRAUGOTT; TROUSDALE, 2013), we point out the difference between reanalysis and neoanalysis within the raised trajectories. We used the verb crer (to believe) to demonstrate another analysis about linguistic change involving the verb $>$ discourse marker path. Our referrals are aimed at considering other sources for the emergence of verbal-based markers, different from those that are most widely defended so far.
\end{abstract}

Keywords: cognitive verbs; verb crer; discourse markers; language change; adverbial clause.

\section{Introdução}

Os marcadores discursivos são formas linguísticas revestidas de um notável valor pragmático. Bybee (2020, p. 448), por exemplo, define a classe dos marcadores como "expressão que fornece indícios pragmáticos sobre como se espera que um enunciado ou partes dele seja interpretado no contexto discursivo". Seu uso é manejado pelo falante, dado que, ao construir suas proposições, ele utiliza um certo marcador para sinalizar aspectos como a relação entre os interlocutores, aberturas e trocas de turno, para mostrar acordo ou discordância com o que o outro diz etc.

Conforme Bybee (2020), Fraser (1996) e Schiffrin (1987), marcadores discursivos são essencialmente uma classe pragmática, não morfossintática, já que vocábulos muito diversos entre si podem ser marcadores. Risso (2019) destaca que diferentes classes de palavras podem ser recrutadas para funcionarem como marcadores discursivos, como advérbios, conjunções, adjetivos e verbos.

Nossa atenção, neste artigo, desloca-se para um marcador discursivo de base verbal, a saber o verbo $\mathrm{Crer}^{3}$. A forma que se mostra relevante para a mudança linguística que

3 Os traços definidores dos marcadores discursivos podem contemplar ou não casos como o do verbo crer. Para autores que consideram esses marcadores como elementos mais esvaziados de significado, a rotulação de creio como MD pode soar incoerente. Porém, há vários trabalhos que admitem verbos com comportamento como o que se vê em (01) e (02) como marcadores, o que será mais bem visualizado adiante. 
pretendemos enfocar é a de primeira pessoa do singular no presente do indicativo, tal como se vê nas ocorrências a seguir, retiradas do Corpus do Português (DAVIES; FERREIRA, 2006) 4 :

1. Ela está grávida de três meses, creio. (18:Azevedo:Sogra)

2. É o mesmo princípio que pode existir no que vocês chamam, eu creio, hoje, de esportes extremos (amorporgaia.blogspot.com)

A expressão (eu) creio, nos dois casos, manifesta um comportamento de marcador, sobretudo, por dois fatores: pela quebra sintática e de tópico ${ }^{5}$ que se observa entre ele e a estrutura canônica da oração e por representar a atitude dos falantes acerca do conteúdo proposicional presente nos eventos comunicativos. Nesses casos, o marcador prestase a sinalizar a incerteza sobre o conteúdo da proposição, estratégia, que, analisada de forma ampla, minimiza seu impacto e possível responsabilidade imputada ao emissor. De outra forma, a mesma expressão ajuda a manter aberto o canal comunicativo, já que a não assertividade gera uma tolerância no receptor, caso ele não concorde com o emissor e/ou esse último se mostre equivocado sobre algo (REGINATTO; FORTILLI, 2019).

Esses usos foram entendidos, por autores brasileiros interessados em mudanças que levam verbos a setornarem marcadores, majoritariamente, como fruto de gramaticalização da oração matriz (GONÇALVES, 2003; CASSEB-GALVÃO, 1999; FREITAG, 2003; FORTILLI, 2015 e outros). Com base nessa tradição, entenderíamos (eu) creio como uma antiga oração matriz (eucreio que $X$ ) que encaixava uma subordinada. No percurso, a subordinada tornar-se-ia absoluta e a matriz, um marcador. Uma segunda possibilidade, advinda de Brinton $(1996,2008,2017)$, mostra que verbos operando como marcadores podem ser resquícios de orações adverbiais ou relativas, isto é, seu surgimento nada teria a ver com a oração principal e com a reanálise de sua suposta condição de encaixador. Nosso objetivo geral é, portanto, comparar essas duas hipóteses de mudança, observando, por meio do marcador selecionado, a definição de reanálise/neoanálise nas discussões mais recentes sobre mudança linguística na perspectiva cognitiva-funcional de língua.

40 Corpus do Português é uma base de dados muito utilizada para investigação linguística, pela sua amplitude e disponibilização on-line. Há, nele, 45 milhões de palavras, apresentadas em milhares de enunciados de diferentes gêneros textuais do português, representativos dos séculos XIII ao XXI. Embora a base não exiba critérios rígidos de quantidade de dados por gênero, século, rigor na compilação das amostragens etc., acreditamos que a natureza da nossa pesquisa, sem aferição de frequência, por exemplo, não é afetada pelas características do córpus.

5 Jubran (2006), ao tratar dos parênteses, assinala a quebra tópica como um de seus traços definidores. Embora nosso trabalho seja sobre marcadores discursivos, pode-se perceber neles essa mesma característica, dado que Jubran (2019, p. 295), em trabalho posterior, apresenta marcadores como uma das classes envolvidas na formação da parentetização. 
Para atingir tais intentos, nossa primeira seção é direcionada a mostrar a hipótese da oração matriz, com a presença de alguns trabalhos brasileiros que se dedicaram à emergência de marcadores via orações matrizes. Em seguida, há a apresentação da hipótese da oração adverbial/relativa. Salientamos, em seguida, o percurso metodológico tomado neste artigo. Na quarta, exibimos o diálogo entre as duas hipóteses com as ocorrências do verbo crer em alguns períodos da história do português. Tecemos as considerações finais em seção própria e, por fim, são apresentadas as referências.

\section{A hipótese da oração matriz}

A hipótese da oração matriz será aqui representada pelo conhecido estudo de Thompson e Mulac (1991), elaborado dentro dos estudos de mudança por gramaticalização. Os verbos que funcionam como marcadores discursivos são considerados mais gramaticais do que os seus usos plenos e prototípicos, dado que seu comportamento se assemelha à classe dos advérbios e serve a aspectos estruturantes do próprio evento comunicativo.

Os autores concebiam um cline de mudança para marcadores de base verbal, tendo como fonte uma oração matriz com um complemento oracional. Pesquisas brasileiras que enfocaram marcadores desse tipo defenderam que certos usos, quase sempre os mais recentes na história da língua, podiam ser explicados nos mesmos moldes, mostrados a seguir.

3. I think that we're definitely moving towards being more technological. (THOMPSON; MULAC, 1991, p. 313, grifos nossos)

Acho que definitivamente estamos caminhando para ser mais tecnológicos.

4. I think Ø exercise is really beneficial, to anybody. (THOMPSON; MULAC, 1991, p. 313, grifos nossos)

Eu acho $\emptyset$ o exercício é realmente benéfico para qualquer pessoa.

5. It's just your point of view you know what you like to do in your spare time I think. (THOMPSON; MULAC, 1991, p. 313, grifos nossos)

É apenas o seu ponto de vista, você sabe o que gosta de fazer no seu tempo livre, eu acho.

Thompson e Mulac (1991) analisaram uma sequência de combinações de sujeito e verbo nas interações do inglês. Os verbos to think e to guess foram os mais frequentes, fato que os fez entender que casos como (5), revestidos de valor de marcador, seriam mais gramaticalizados do que os usos em (3) e (4). A partir de um conjunto de dados do inglês falado, eles propuseram estágios de mudança que partiriam da oração encaixada (3) e seguiriam até a transformação em MD (5). 
Um dos fenômenos possibilitadores, no inglês, foi o That-deletion, recurso próprio daquela língua que possibilita às expressões com verbos encaixadores dispensarem o complementizador. Em (4), vemos, na tradução aproximada, como seria a matriz eu acho sem a presença do complementizador que. Esse estágio, visto como o $2^{\circ}$ passo de mudança pelos autores, mostra ainda uma oração principal, dada a permanência da relação sintática de complementação.

O último estágio, totalmente gramaticalizado, mostra-se quando a antiga oração (eu) acho funciona como marcador, desvinculando-se sintaticamente do que era o seu complemento oracional. Nesse percurso conceptualizado por Thompson e Mulac (1991), na passagem do encaixador a marcador, ocorre uma inversão da hierarquia sintática, pois a oração subordinada transforma-se em absoluta e autônoma. Assim, o cline defendido por eles baseia-se em: a) oração matriz encaixando um complemento oracional por complementizador; b) oração matriz encaixando um complemento com a ausência de marca explícita/complementizador e c) a oração absoluta relacionando-se ao marcador discursivo, seu antigo encaixador.

Explicações como a dos autores alinham-se a uma visão difundida por Hopper (1991), sobre a gramaticalização na sincronia. A hipótese da oração matriz é o caminho de mudança mais usado nos trabalhos que têm a gramaticalização como quadro teórico principal para explicar mudanças envolvendo verbos na língua portuguesa. CassebGalvão (1999), por exemplo, ao analisar achar no português, apresenta usos em que o elemento funciona de maneira próxima aos advérbios, identicamente ao que é sustentado por Thompson e Mulac (1991), sobretudo, quando o verbo ostenta uma livre posição na oração.

Na mesma linha, Gonçalves (2003) descreve ocorrências com o verbo parecer. O autor (2003) assume que parecer não apresenta uma fixidez sintática enquanto marcador, o que o leva a comportamentos semelhantes aos encontrados por Thompson e Mulac (1991) em seus dados, tendo como fonte as sentenças encaixadas. Em trabalho mais recente, utilizando um conjunto de verbos cognitivos, Barbosa-Santos (2019) verificou, dentro do quadro da gramaticalização, o percurso de verbos como achar, imaginar, crer, e outros, no português. A autora, igualmente utilizando a hipótese das orações matrizes, sustenta que essas últimas são as fontes dos parentéticos epistêmicos em casos como "a maioria de vocês, imagino, estuda ou trabalha" (BARBOSA-SANTOS, 2019, p. 12).

Os parentéticos epistêmicos são elementos portadores de modalidade epistêmica que se alocam no enunciado promovendo a ruptura no seu curso natural. Além desse traço sintático, há parâmetros textuais para elucidar a atuação dos parênteses. Jubran (2006) explica-os como uma breve suspensão do tópico discursivo, que não constitui uma nova centração tópica e não afeta a coesão daquele tópico dentro do qual ocorre. Ao estabelecer a constituição formal dos parênteses, Jubran (2019) apresenta cinco 
configurações possíveis para a natureza da parentetização: marcadores discursivos, sintagmas nominais, frases simples, frases complexas e pares adjacentes. Conforme sinaliza a autora, "os parênteses podem ser constituídos por marcadores discursivos ou por unidades limítrofes à classe dos marcadores" (JUBRAN, 2019, p. 296), asserção que evidencia que o tratamento da parentetização, tida como um processo constitutivo do texto, acaba contemplando os marcadores discursivos pelo fato de os últimos consolidarem certos parênteses. A autora utiliza um caso do verbo acreditar como exemplo:

6. Doc. - o senhor falou que o presidente pode estabelecer regras... normas... de: em torno do sindicato que ele: preside... essas normas ele decidiria só? sozinho ele decidiria eu quero que seja feito isso isso isso e isso?

Inf. - normalmente existe... acredito eu... um colegiado... é graças a este colegiado... que o senhor presidente vai evidentemente pautar: suas decisões... porque evidentemente nós temos que admitir... que um indivíduo... não tem condições... de resolver: todas aquelas questões... atinentes ao sindicato. (JUBRAN, 2019, p. 297, grifos da autora)

A atuação textual-interativa de acredito eu, acima, pauta-se, segundo a autora, na manifestação atitudinal do locutor em relação ao tópico, isto é, "um locutor [que] relativiza o teor de certeza sobre a veracidade do conteúdo do enunciado escopado pelo parêntese" (JUBRAN, 2019, p. 318).

A seguir, será apresentada a segunda explicação possível para a atuação de verbos cognitivos, em especial, o crer, como MD.

\section{A hipótese da oração adverbial ou relativa}

A outra hipótese tratada neste artigo tem os trabalhos de Brinton (1996, 2008, 2017) como base. A fonte dos marcadores em questão, neste outro caminho, são orações mais periféricas, como as adverbiais e as relativas. Os estudos dessa autora enfatizaram dados diacrônicos, o que é um ponto de diferenciação entre sua pesquisa e as de Thompson e Mulac (1991). Apesar disso, a relação entre esses estudos parece válida porque a base de ambos é o processo de gramaticalização, além de o objeto serem verbos parecidos, como se verá abaixo.

Em 2008, Brinton analisou dois verbos do inglês, to gather e to find, não prototípicos dos marcadores verbais, uma vez que os que costumam ser apontados como mais frequentes são, por exemplo, to think e to guess. A autora verificou que, ao contrário de afırmações como de Wierzbicka (2006), que defendia a emergência desses verbos a partir do século $\mathrm{XVIII}$, usos de to gather e to find podem ser rastreados antes desse período. Sua forma mais antiga não continha indícios de que seu início se pautou em formas encaixadoras, ao contrário, havia, em períodos anteriores, como no século XVI, formas expressas por 
orações adverbiais, sobretudo, iniciadas pelas conjunções do inglês as ou so. Para os dois verbos, as descobertas da pesquisa foram semelhantes.

A autora nota que as orações adverbiais contemplam traços que se relacionam melhor à emergência dos marcadores construídos por esses verbos, pois, como geralmente é defendido nos trabalhos de mudança (cf. HOPPER; 1991; HOPPER; TRAUGOTT, 2003), a forma antiga pode se enfraquecer em termos de uso devido à emergência de um novo emprego. Destaca-se que orações adverbiais com o verbo to find caem em desuso no mesmo período em que a frequência de suas formas como marcador aumenta. A autora traz os seguintes dados:

7. Both of French and of Germayn kynde Was pis man ... and ferpermor,

as I fynde, Whan in his modir newly conceyved was he (BRINTON, 2008, p. 235)

Este homem era de sangue francês e alemão... e, além disso, como descobri, quando, em sua mãe, ele foi recém-concebido...

8. The time's at hand my lord, the enemy hearing of succours daily flocking to us, is marching, as I gather, towards our camp. (BRINTON, 2008, p. 228)

O tempo está próximo, meu senhor, o inimigo ouvindo sobre socorros que diariamente se dirigem a nós, está marchando, como eu percebo, em direção ao nosso acampamento.

Não se sabe, até aqui, se verbos do português como descobrir e perceber, próximos semanticamente a to find e to gather poderiam ter usos como marcadores. Brinton (2008) defende que é por meio desses usos, como orações adverbiais, que os marcadores baseados nos verbos em questão emergem na língua inglesa.

Em trabalhos de 1996 e 2017, a autora focaliza os marcadores que são mais prototípicos, aqueles que são formados pelos verbos to think, to guess, to believe, entre outros. Ao contrário dos resultados de outros autores que salientaram os mesmos predicados, seus resultados são semelhantes aos apurados para to gather e to find. Segundo Brinton, ocorrências ainda no inglês médio podem ser mapeadas, como as que vêm a seguir.

9. And I shal swich a feeste and revel make/ That, as I trowe, I shal the Sowdan quite. (BRINTON, 2017, p. 148, grifos nossos)

E eu farei tal festa e festejo que, como eu acredito, eu devo retribuir ao Sultão

10. Now wolde som men waiten, as I gesse,/That I sholde tellen al the purveiance (BRINTON, 2017, p. 150, grifos nossos)

Agora, alguns homens esperariam, como eu acho, que eu deveria contar a todas as provisões 
Essas duas ocorrências, encontradas pela autora, são do século XIV. Ela enfatiza que a emergência de marcadores, se pautada nesse tipo de dado, não contempla a correlação clara entra as etapas propostas por Thompson e Mulac (1991). Seu argumento é que a diacronia do inglês não respeita etapas, em tese, não podem se sobrepor. Para Brinton, essa forma mais antiga, vista em (9), por exemplo, transfigura-se no uso como MD, sem indícios de conexão oracional e alicerçado apenas no verbo. Esse cenário da história do inglês indica, segundo a autora, que:

O surgimento de parentéticos parece ser fortemente influenciado pela existência de orações adverbiais com as ou so, que podem ser rastreadas até o inglês antigo. Nesta visão, o desenvolvimento de parentéticos sem as ou so envolve o simples apagamento do conector adverbial, por exemplo:

Para treze anos é um convento, como eu acho > Para treze anos é um convento, eu acho $^{6}$ (BRINTON, 2017, p. 160).

Investigaremos, adiante, se há fatores que sugerem a possibilidade de visualizar uma ou outra trajetória para o creio, do português, por meio de um recuo temporal.

Vale ressaltar que, de uma forma ou de outra, quando atuando como marcador discursivo, o verbo em questão está sendo manejado, pelo falante, de uma forma diferente daquela ditada pelos seus traços originais. Isso sugere uma nova análise, ou uma reanálise, como se vinha denominando. Em Langacker (1977), a reanálise sintática era entendida como a mudança na estrutura sintática sem uma alteração direta na estrutura de superfície.

Com o seguimento dos estudos de gramaticalização, uma sequência de autores (HEINE; REH, 1984; HASPELMATH, 1998; LIGHTFOOT, 1999) tem debatido que a reanálise é entendida a partir de mudanças grandes, e não tão graduais. Haspelmath (1998), por exemplo, desconsidera a relação entre reanálise e gramaticalização por aquela ser abrupta.

Um exemplo de cline bem conhecido na gramaticalização, que pode representar esse tipo de mudança em grande escala, concebido pela reanálise, é o de nominalização de Lehmann (1988). Entre duas estruturas que podem ser funcionalmente equivalentes, a mais gramaticalizada é posterior à menos gramaticalizada. Mesmo que apresentem certas diferenças, elas podem ser relacionadas e explicadas pela reanálise. O cline de nominalização, por exemplo, em Lehmann (1988), traz os estágios que levam uma oração subordinada a reduzir-se a apenas um nome, seu correspondente:

6 No original: "Thus, the rise of parentheticals seems to be heavily influenced by the existence of adverbial clauses with as or so, which can be traced back to Old English. In this view, the development of parentheticals without as or so involves simple deletion of the adverbial subordinator, e.g.: For thrittene is a covent, as / gesse > For thrittene is a covent, I gesse". 
11. a) encaixada verbal finita; b) encaixada verbal não-finita e c) encaixada nominalizada.

Parreira (2018, p. 19) traz exemplos do português para cada um desses estágios:

12. a) eu vi [que Maria saiu]; b) eu vi [Maria sair] e c) eu vi [a saída de Maria].

A oração que Maria saiu torna-se nominalizada em a saída de Maria. A mudança em grande escala mostra que tais orações no cline têm estruturas diferentes umas das outras, embora tenham certa equivalência funcional.

A neoanálise direciona a mudança em pequena escala, a micro passos de mudança, seja na forma ou no significado (TRAUGOTT; TROUSDALE, 2013). Os autores apresentam, por exemplo, o uso do quantificador a lot of no inglês. Um micro passo sintático ocorre quando of passa a atrelar fonologicamente a lot e não ao sintagma nominal sequente. A forma partitiva antiga, no uso, a lot of land tem of ligado a land, a mudança em pequena escala representa uma forma neonalisada que of se atrela a lot. Assim, a lot of quantificador se torna mais fixo em suas partes, ao contrário de sua forma antiga.

A seguir, passamos à metodologia de coleta de dados, os quais podem indiciar ou não um novo olhar sobre o "ponto zero" do percurso que levou crer a se tornar marcador discursivo.

\section{Metodologia}

Diante das duas propostas de explicação da mudança que leva o verbo crer ao comportamento de marcador discursivo, utilizaremos um conjunto de ocorrências de outras sincronias do português, diversas da atual, para verificar indícios de alinhamento à hipótese da oração matriz ou à outra trajetória possível.

Como já foi dito, a maior parte dos trabalhos brasileiros adota a hipótese da oração matriz (CASSEB-GALVÃO, 1999; GONÇALVES, 2003; FORTILLI, 2015; BARBOSA-SANTOS, 2019), razão pela qual alguns pontos dessas pesquisas serão mencionados na análise.

O córpus escolhido foi o Genre/historical do Corpus do Português, que disponibiliza quatro corpora distintos para fins de pesquisa, oferecendo, ao usuário, a comparação da frequência e da distribuição de palavras, frases e construções gramaticais entre padronizações de textos por:

a. Registro: compilado de textos coloquiais, ficcionais, jornalísticos e acadêmicos; 
b. Dialeto: reúnem dados do Português europeu e brasileiro;

c. Período histórico: periodização entre diferentes séculos (do XIII ao XX).

Optamos pela coleta de dados de maneira histórica, utilizando o córpus Genre/Historical porque o que se quer é verificar como o verbo crer vinha sendo utilizado antes de se firmar como marcador discursivo. Para a coleta, ainda não exaustiva ${ }^{7}$, foi selecionada a forma em primeira pessoa do verbo crer tanto na sua grafia anterior creo quanto na sua escrita atual creio.

O tratamento dos dados é essencialmente qualitativo, já que olhar para os séculos anteriores, abarcados pelo Genre/Historical, revela uma tentativa de, pelas características das ocorrências mais antigas envolvendo o verbo, perceber pistas sobre a fonte do marcador. Assim, o critério de coleta foi selecionar todas as ocorrências com o verbo creo/creio funcionando como núcleo da oração matriz, a fim de contemplar a hipótese de Thompson e Mulac (1991), e atuando como componente de orações adverbiais ou relativas, para ilustrar a hipótese de Brinton $(1996,2008,2017)$. Como este trabalho não intenta determinar cabalmente a origem de creio $_{\mathrm{MD}^{\prime}}$ sua presença nos diferentes tipos de oração (matriz, adverbial e relativa) traduz-se em indícios a serem usados em pesquisa maior.

\section{Análise}

Para discutir as duas hipóteses, a reanálise é um mecanismo de mudança que precisa ser retomado. Na hipótese da oração matriz, a reanálise ocorre quando a forma mais gramaticalizada é reanalisada a partir da forma menos gramaticalizada. Assim, a oração matriz encaixando uma subordinada com ausência do complementizador é vista como a reanálise daquela oração em que esse ocorre. No mesmo caminho, o uso de marcador, antes núcleo da matriz, escopando uma oração absoluta é a estrutura reanalisada da oração matriz encaixando uma subordinada com ausência do complementizador. Partindo dos casos abaixo, se tomada essa primeira hipótese de mudança, (14) é reanalisado com base em (13) e (15) com base em (14).

13. Creio que a solução não está nem na estatização nem na privatização (190r:Br:Intrv:Pov)

14. *Creio a solução não está nem na estatização nem na privatização

7 O conteúdo deste trabalho está alocado em pesquisa maior, sobre o verbo crer, ainda não finalizada. 
15. Há nove anos ela não participava dum filme e este, creio, é o melhor de sua carreira (190r:Br:Intrv:ISP)

Uma característica que há no inglês e não ocorre no português é o fenômeno da ausência do complementizador, o That-deletion. Não há uso documentado com o apagamento do complementizador e manutenção da posição inicial comum para as orações matrizes, como em (14). Assim, os três estágios concebidos por Thompson e Mulac (1991) não podem ser totalmente aplicados aos casos com verbos encaixadores do português.

Barbosa-Santos (2019), por exemplo, apresenta a hipótese da oração matriz para o estudo de alguns verbos cognitivos que se tornam parentéticos epistêmicos, mas observa, na trajetória dos mesmos, manifestação apenas do primeiro estágio e do terceiro. Considerando a reanálise, tal como ela vinha sendo investigada, isso é possível, dado que, com ou sem a fase intermediária, as duas estruturas são equivalentes funcionalmente e uma tem um grau de gramaticalidade maior do que a outra. Desse modo, mesmo que não ocorra o segundo estágio, aceitar que as mudanças podem ser em escala maior, sem tantos micropassos, torna viáveis análises como a dessa última autora, ao defender a mudança em dois passos: de oração encaixada com complementizador > marcador.

Esse quadro se torna um pouco diferente se tomarmos algumas pesquisas recentes, que revisam as questões relativas à formação de significados mais gramaticais, sobretudo pela observação da neoanálise. Para Traugott e Trousdale (2013, p. 36), a neoanálise é um "micropasso em uma mudança construcional [...], seja de forma ou de significado"8. Os autores defendem que neoanálise são sucessões de pequenos passos, relacionados para que a mudança mais global possa ocorrer. Diferentemente do entendimento sobre reanálise, a neoanálise diverge da ideia de mudança mais abrupta, ou em grande escala, pois alterações mínimas que ocorrem no desenvolvimento geral das formas linguísticas são neoanalisadas.

A neoanálise não se ajustaria bem ao cline de Thompson e Mulac (1991), se tomássemos como base casos do português, pela ausência de um estágio intermediário no possível trajeto entre a suposta estrutura encaixadora e o funcionamento como marcador discursivo, o que destoa da ideia de micropassos.

Na hipótese da oração adverbial, há um cenário diferente se pensarmos sobre a aplicação da reanálise e da neoanálise. Brinton $(1996,2008,2017)$ defende dois estágios principais: um em que as expressões são as orações adverbais e o segundo com a presença dos marcadores discursivos "equivalentes". Parece-nos que os dois usos podem ser, de fato, mais próximos, pela existência de algumas características sintáticas presentes tanto no uso fonte como no uso alvo, o emprego como marcador.

8 No original: "micro-step in a constructional change [...] whether of form or of meaning". 
A livre posição dentro da oração, por exemplo, é presente nos dois usos, dado que o caráter periférico de advérbios e das orações adverbiais permite ao falante alocar o elemento em questão em posições diferentes no enunciado. Com a finalidade de esclarecer o que se está dizendo, trazemos o caso a seguir:

16. Quem nesta vyda cuydar pode bem çerto saber quee gram trabalho vyuer. Quem cuidar nesta mudãça queste triste mundo faz achara que nele jaz a mayor desconfyança. [...] Cada hû em sseu estado meta bem a mão no sseo achara ssegundo creo muyta dor muyto cuydado. (15:Resende:Cancioneiro)

Transcrição: "Quem, nesta vida, imagina, pode certamente ter ciência que grande trabalho existe. Quem pensa nesta mudança que este triste mundo faz, tinha encontrado que, nele, estende-se a maior desconfiança. [...] Cada um, em seu conjunto de qualidades e características, pôs com propriedade a mão no seu [mundo], e tinha encontrado, segundo creio, muita dor e muita precaução."

Uma segunda característica que é presente tanto no uso fonte quanto no uso alvo, o de MD, é a própria parentetização. Repetimos, aqui, o exemplo de Brinton (2017, p. 160):

\section{7. para treze anos é um convento, como eu acho}

\section{8. para treze anos é um convento, eu acho}

Observando esses casos, pode-se pensar que a mudança, como concebida por Brinton, é mais processual, em pequena escala ou em passos mínimos. As duas estruturas têm posições periféricas em relação à oração matriz, com diferença estrutural apenas na presença e ausência da conjunção. Diferentemente do que se afirmava em Thompson e Mulac (1991), sobre perda de complementizador seguida de inversão da hierarquia sintática das partes envolvidas, a hipótese da oração adverbial aposta em um pequeno passo de mudança, pois a oração matriz não perde tal estatuto, nem tampouco a oração margem/adverbial muda drasticamente sua condição. Todo esse processo parece se presentificar no caso abaixo:

19. em aquela casa que chamom Edepol, hu esteverom juntos, segundo creo, e quantas cousas ali forom ditas (14:Boosco)

20. isto tem uma influência muito grande eu creio (190r:Br:LF:SP) 
Thompson e Mulac (1991) entendem que orações matrizes sem o complementizador preservavam seu lugar no âmbito das estruturas de complementação. Thompson (2002), uma década após, defendeu que casos de orações iniciais sem o complementizador não deveriam caber em uma análise sobre complementação e usou diversos critérios para verificar se esses complementos poderiam ser objetos ou uma categoria unitária, chegando à consideração de que os usos, identificados com o estágio dois da hipótese da oração matriz, deveriam ser vistos já como marcadores totalmente independentes. A perspectiva de Thompson (2002) nos leva a pensar que talvez os estágios dois e três do cline, propostos por Thompson e Mulac (1991), sejam complementares, não sendo um mais gramaticalizado do que o outro, em dados do português. Cristiano (2021), analisando o desenvolvimento do marcador pode crer, também defende que usos do marcador em posição inicial da sentença sem o complementizador não revelam conservação de traços e estatuto de oração matriz, ao contrário, indicam já uma atuação como marcador discursivo.

Em períodos passados do português, é possível encontrar ocorrências de creo em orações adverbiais conformativas (como eu creio/segundo creio e variações), como abaixo:

21. Na tenda nom ficou pano nem cordas nem guarnimento que toda nom foss'a dano, pelo apoderamento da Meestra, que, tirando foi tanto pelo esteo, que por esto, com'eu creo, se foi toda espeçando. (Cantigas1)

22. A Virgen mui groriosa... E pois en toda ssa vida, per com achei, serviu a Santa Maria, Madre do muit' alto Rei, que o levou pois conssigo, per com' eu creo e sei, deste mund' a Parayso (Mettman:CantigasSM1)

23. Mays eu sey ben, segundo creo, que, ante que elles o ajan morto ou preso, cõmo elles queríã, ante fará taes esporoadas et taes feytos et taes entradas et taes caualarías que el meesmo tomará pauor en ssy (13:CronTroyana)

24. E, segundo quanto eu creo, ben pareçe a nós todos que disse ben. (13:CronTroyana)

As duas primeiras, (21) e (22), são do século XIII, e as duas últimas do século XIV. Algumas características podem ser vistas nesse conjunto. Com'eu creo tem a configuração de parêntese, pois se mostra como uma suspensão no desenvolvimento tópico, pela qual o falante insere elemento denotador de conformidade, ajuste do que se fala às suas próprias crenças e opiniões. Ainda, marca uma posição circunstancial semelhante aos usos como marcador na história mais recente da língua. 
Segundo quanto eu creo e segundo creo operam também como suspensão do tópico, isto é, uma interrupção no curso de desenvolvimento do conteúdo da proposição, para a saliência de um dado sobre o locutor, qual seja o amparo do que se diz nas suas crenças. Em (23), segundo creo é medial, enquanto em (24) é anterior ao conteúdo proposicional que será proferido. Essa variabilidade sintagmática se assemelha à variabilidade já encontrada nos usos de marcadores nos trabalhos brasileiros. Se as orações adverbiais forem vistas como fontes, como defende Brinton (2017, p. 161), vê-se que elas podem "envolver o apagamento do conectivo adverbial em casos em que a conexão lógica da oração adverbial e principal é contextualmente inferível"9. Expressões/marcadores com o crer podem ser vistas/os na exata posição que a oração adverbial conformativa ocupava. É o que se vê abaixo:

25. a coisa não faz muita diferença para ti, creio eu (18:Garrett:Arco)

26. Mas o meu namorado, creio, está pensando em me trair. Aíestá o mistério (18:Azevedo:Filha)

27. Amara à Margarida em demasia, creio, e o vigor nervudo e musculento da herdeira do marinheiro Reginaldo Venceslau era como (18:Oliveira:Guidinha)

Essas três ocorrências são do século XIX. Podemos observar que os usos em que a oração funciona como marcador se assemelham com a natureza adverbial das ocorrências que estão expostas um pouco mais acima, de (21) a (24). Parece haver mais semelhanças sintáticas entre a coisa não faz muita diferença para ti, [creio eu] [como eu creio] [segundo eu creio] do que entre uma suposta oração matriz e o marcador (creio eu que a coisa não faz muita diferença e a coisa não faz muita diferença, creio eu), sobretudo, por um fator: o apagamento de conjunções mais periféricas (como, segundo e conforme) parece uma mudança mais sutil, uma espécie de micropasso. Já a perda da conexão entre duas orações, ou seja, do que, que articularia uma matriz e uma completiva, soa como uma alteração de grande monta, um passo que desemboca, inclusive, na transformação de uma oração dependente em autônoma e no total deslocamento do verbo, supostamente, antigo encaixador.

Nos dados atuais do português, eu creio, creio eu e creio ${ }^{10}$ seguem funcionando como marcadores discursivos, como se vê abaixo

9 No original: "It merely involves deletion of an adverbial connective in cases where the logical connection of main and adverbial clause is contextually inferable".

10 Pode haver distinção, em algum âmbito, entre as três formas do MD atualmente, mas sua especificação não é alvo deste artigo. 
28. tem um pouco a ver com a descrença, eu creio, com o facto de, hoje em dia, por exemplo, (190r:Pt:Intrv:Web)

29. Eu era muito criança, devia ter.. quinze anos, creio eu, nessa época (19:Fic:Br:Penna:Menina)

30. e dessas leituras várias, mas bem orientadas, me ficaram, creio, uma estesia e um estilo (19:Fic:Br:Rio:Momento)

O intuito neste trabalho não foi defender de imediato uma trajetória outra (diferente da que já é bem aceita nos estudos do fenômeno) para os marcadores discursivos de base verbal, pois a investigação sobre tal possibilidade ainda é inicial. Procuramos apresentar, somente, algumas pistas que apontam a coerência de se repensarem as trajetórias já tão consagradas para os verbos do português que passam a marcadores discursivos. Tendo como ponto de partida os estudos de Brinton (1996, 2008, 2017), mesmo no quadro da gramaticalização, pode ser possível uma reinterpretação dos casos em um quadro mais recente de mudança, por exemplo, por meio da abordagem cognitiva-funcional que, dentre seus trabalhos, comporta os que apostam em micropassos e neoanálise.

\section{Considerações finais}

Majoritariamente, trabalhos brasileiros (CASSEB-GALVÃO, 1999; GONÇALVES, 2003; FORTILLI, 2015; BARBOSA-SANTOS, 2019) assumem a oração matriz (THOMPSON; MULAC, 1991) como fonte para marcadores discursivos como achar, parecer, supor, imaginar, entre outros. Com base nesse cenário, buscamos, aqui, apresentar outro olhar sobre os mesmos casos, presente na literatura sobre mudança por gramaticalização.

Inicialmente, a hipótese da oração matriz estabelece três etapas. Uma delas não é encontrada na língua portuguesa, o que gera a primeira discussão sobre esse caminho. Os trabalhos já realizados mostram os verbos, supostamente encaixadores, atuando na etapa um, com esse valor, e na etapa três, já como marcadores discursivos.

As proposições de Brinton (1996, 2008, 2017), à luz da hipótese da oração adverbial e da oração relativa, parecem se encaixar, além da língua inglesa, também à língua portuguesa por: a) favorecer micropassos de mudança, identificados com a neoanálise e b) alinhar o comportamento dos marcadores discursivos, que tendem a ser parentéticos, a orações adverbiais, que também tendem a esse comportamento sintático. 
Nesse momento, apresentamos uma breve discussão e uma amostra de dados, ambas destinadas a sinalizar uma possível releitura de casos já analisados. 0 andamento de nossas pesquisas, amparado em maior volume de dados e análises mais profundas, poderá, futuramente, validar ou refutar essa primeira reflexão.

\section{REFERÊNCIAS}

BARBOSA-SANTOS, L. A. O uso de verbos cognitivos em construções parentéticas epistêmicas: uma abordagem do ponto de vista da gramaticalização. 2019. Dissertação (Mestrado em Letras) -Universidade Federal de Mato Grosso do Sul, Três Lagoas, 2019.

BRINTON, L. J. The Evolution of Pragmatic Markers in English: Pathways of Change. Cambridge: Cambridge University Press, 2017. DOI: 10.1017/9781316416013

BRINTON, L. J. The comment clause in English: syntactic origins and pragmatic development. Cambridge: Cambridge University Press, 2008. DOI: 10.1017/CBO9780511551789

BRINTON, L. J. Pragmatic markers in English: grammaticalization and discourse functions. Berlin: Mouton de Gruyter, 1996. DOI: 10.1515/9783110907582

BYBEE, J. Mudança Linguística. Tradução Marcos Bagno. Petrópolis: Editora Vozes, 2020.

CASSEB-GALVAO, V. C. O 'achar' no Português do Brasil: um caso de gramaticalização. 1999. Dissertação (Mestrado em Linguística) - Instituto de Estudos da Linguagem, Universidade Estadual de Campinas, Campinas, 1999. Disponível em: http://repositorio. unicamp.br/jspui/handle/REPOSIP/271021. Acesso em: 01 out. 2020.

CRISTIANO, L. B. Uma análise de pode crer à luz dos modelos baseados no uso. 2021. Dissertação (Mestrado em Letras) - Universidade Federal de Mato Grosso do Sul, Três Lagoas, 2020.

DAVIES, M.; FERREIRA, M. Corpus do Português: 45 million words, 1300s-1900s. Brigham Young University: Provo-UT, 2006-. Disponível em: http://www.corpusdoportugues.org. Acesso em: 28 set. 2020.

FORTILLI, S. C. Parentetização de verbos de atividade mental no português falado e escrito. In: VII SINEFIL, 2015, Campo Grande. Revista Philologus, 2015. p. 1067-1077.

FRASER, B. Pragmatic markers. Pragmatics, v. 6, n. 2, p. 167-190, 1996. 
FREITAG, R. M. K. O papel da frequência de uso na gramaticalização de acho (que) e parece (que) marcadores de dúvida na fala de Florianópolis. Veredas, Juiz de Fora, v. 7, n. 1 e n.2, p. 113-132, jul./dez. 2003.

GONÇALVES, S. C. L. Gramaticalização, modalidade epistêmica e evidencialidade: um estudo de caso no português do Brasil. 2003. Tese (Doutorado em Linguística) - Instituto de Estudos da Linguagem, Universidade Estadual de Campinas, Campinas, 2003. Disponível em: http://repositorio.unicamp.br/jspui/handle/REPOSIP/270368. Acesso em: 07 out. 2020.

HASPELMATH, M. Does grammaticalization need reanalysis? Studies in Language, v. 22, p. 315-351, 1998. DOI: 10.1075/sl.22.2.03has

HEINE, B.; REH, M. Grammaticalization and Reanalysis in African Languages. Hamburg: Buske, 1984.

HOPPER, P. J. On Some principles of grammaticization. In: TRAUGOTT, E. C.; HEINE, B. (ed.). Approaches to grammaticalization. Amsterdan: John Benjamin, 1991. p. 17-35. DOI: 10.1075/tsl.19.1.04hop

HOPPER, P.; TRAUGOTT, E. Grammaticalization. Cambridge: Cambridge University Press, 1993. DOI: $10.1017 /$ CBO9781139165525

JUBRAN, C. C. A. S Parentetização. In: JUBRAN, C. C. A., KOCH, I. G. V. (org.). Gramática do Português Culto Falado no Brasil: construção do texto falado. v. I. Campinas: Editora da UNICAMP, 2006. p. 301-357.

JUBRAN, C. S. Parentetização. In: JUBRAN, C. S. A construção do texto falado. São Paulo: Contexto, 2019.

LANGACKER, R. W. Syntactic Reanalysis. In: LI, C. (org.). Mechanisms of syntactic change. Austin: University of Texas Press, 1977. p. 53-139.

LEHMANN, C. Towards a typology of clause linkage. In: HAIMAN, J.; THOMPSON, S. A. (ed.). Clause Combining in Grammar and Discourse. Amsterdam: John Benjamins, 1988. p. 181-225. DOI: 10.1075/tsl.18.09leh

LIGHTFOOT, D. J. The development of language: acquisition, change, evolution. Oxford: Blackwell, 1999. 
PARREIRA, A. C. de L. Investigação diacrônica de construções complexas formadas por [[achar] + [predicado não-verbal]]. 2018. Tese (Doutorado em Estudos Linguísticos) Instituto de Biociências, Letras e Ciências Exatas, Universidade Estadual Paulista "Júlio de Mesquita Filho", São José do Rio Preto, 2020. Disponível em: https://repositorio.unesp. br/handle/11449/154338. Acesso em: 04 out. 2020.

REGINATTO, S.; FORTILLI, S. C. Verbos cognitivos parentetizados e funções argumentativas na esfera jornalística. Relatório de Pesquisa. Campo Grande, 2019.

RISSO, M. S. Marcadores discursivos basicamente sequenciadores. In: JUBRAN, C. S. A construção do texto falado. São Paulo: Contexto, 2019.

SCHIFFRIN, D. Discourse Markers. Cambridge: Cambridge University Press, 1987. DOI: $10.1017 / C B 09780511611841$

THOMPSON, S.; MULAC, A. A quantitative perspective on the grammaticalization of epistemic parentheticals in English. In: TRAUGOTT, E.; HEINE, B. (org.). Approaches to grammaticalization. v. 1. Philadelphia: John Benjamins Publishing Company, 1991. DOI: $10.1075 /$ tsl.19.2.16tho

THOMPSON, S. "Object complements" and conversation towards a realistic account. Studies in Language, v. 26, p. 125-164, 2002. DOI: 10.1075/sl.26.1.05tho

TRAUGOTT, E.; TROUSDALE, G. Constructionalization and Constructional Changes. Oxford: Oxford University Press, 2013. DOI: 10.1093/acprof:oso/9780199679898.001.0001 